\title{
Using evidence-based recommendations for guidance, guidelines and scale-up strategies
}

Ian Askew

Population Council

Follow this and additional works at: https://knowledgecommons.popcouncil.org/departments_sbsr-rh

Part of the International Public Health Commons, and the Quantitative, Qualitative, Comparative, and Historical Methodologies Commons

How does access to this work benefit you? Let us know!

\section{Recommended Citation}

Askew, lan. 2013. "Using evidence-based recommendations for guidance, guidelines and scale-up strategies," presentation at the Second Consultation on Developing Standards for Identifying Evidence Based Practices in Reproductive Health, Croydon, UK. 


\section{Using evidence-based recommendations for guidance, guidelines and scale-up strategies}

Ian Askew

Population Council

Second Consultation on Developing Standards for Identifying Evidence Based Practices in Reproductive Health

Croydon, UK, September $18^{\text {th }}-19^{\text {th }} 2013$ 


\section{Framing evidence for developing recommendations}

"A global health evidence framework [is] one which uses multiple domains to arrive at a summary judgment of the evidence for community or population health interventions or programs"

Luoto et al, 2013 


\section{Why use a framework?}

- Systematic and rigorous

- Transparent procedures

- Summary judgment

- Rating across multiple domains

- Quality, quantity, relevance, consistency, context....

- Focus on evidence of effectiveness of an intervention

- Other attributes?

- Types of intervention? 


\section{Multiple frameworks - multiple judgments?}

- Compared 3 interventions

- Household water chlorination to prevent diarrhea

- PMTCT of HIV

- CHWs to reduce childhood morbidity

- Applied six evidence frameworks

- Comparison of summary judgments after rating the evidence

$\Rightarrow$ Variability in grades assigned, sometimes by two or more categories 


\section{Why the differences?}

- Which domains included and how rated:

- Classifying strength of evidence

- Magnitude of benefits vs. harms

- Consideration of context

- Implementation procedures

- Feasibility

- Costs

- Sustainability

- Inter-rater reliability 


\section{Types of evidence summaries and relevance of domains}

- Efficacy of an intervention in meeting health needs of the individual / couple

- Service delivery guidelines

- Effectiveness of delivering interventions at the population level

- Delivery programming guidance

- Sustainability at national / programme level

- Systems strengthening and scale-up / mainstreaming

Feasibility, implementation

Context, cost 


\section{Interventions, evidence frameworks and recommendations}

- Classifying and comparing interventions; asking the right research questions

- Intervention characteristics?

- Population needs?

- Systematic - rigorous - realist review process?

- Grading / rating the evidence according to which domains; weighting the domains?

- Determining a summary judgment

- Preparing and communicating a practice recommendation

$\Rightarrow$ One or multiple frameworks? Or none? 


\section{Using evidence for practice recommendations: Who uses which framework? Or procedure?}

- Globally

- Norm-setting bodies: WHO, FIGO, UNFPA

- Large donors: DFID, USAID, BMGF

- Large INGOs: IPPF, MSI, PSI

- Nationally

- $\mathrm{MOH}$ (with support from....???)

- Professional associations

- Medical training institutions 